\title{
Minimally invasive, robot-assisted iliosacral screw insertion for fusionless fixation in children with neuromuscular scoliosis
}

\author{
Michel Lefranc, MD, PhD, ${ }^{1}$ F. François Deroussen, $M D,{ }^{2}$ and Richard Gouron, $\mathrm{MD}, \mathrm{PhD}{ }^{2}$ \\ Departments of ${ }^{1}$ Neurosurgery and ${ }^{2}$ Pediatric Orthopedic Surgery, Amiens University Medical Center, Amiens, France \\ Fusionless surgery coupled with growing rod techniques is increasingly advocated for the treatment of early-onset sco- \\ liosis in general and neuromuscular scoliosis in particular. lliosacral screws have excellent biomechanical characteristics \\ but are hard to place safely. Here, the authors report on robot-assisted lilosacral screw positioning as part of growing \\ rod surgery for the fusionless correction of early-onset scoliosis. The technique is based on a bilateral double sliding rod \\ construct anchored to the pelvis proximally with 6 hooks or sublaminar bands and distally with iliosacral screws placed \\ by the robot.
}

The video can be found here: https://youtu.be/5HGH_DiD-ck.

KEYWORDS robot; pelvic fixation; early-onset scoliosis; fusionless fixation; iliosacral screw; video 